\title{
Submission of items and documents as a way of gathering evidence in preliminary investigation of a criminal case
}

\author{
S. B. Rossinskiy ${ }^{1}$
}

${ }^{1}$ Moscow State Kutafin Law University, 9 Sadovaya-Kudrinskaya str., Moscow 125993, Russian Federation

DOI: $10.18255 / 1996-5648-2021-2-210-219$

Research article

Full text in Russian

This article is devoted to the consideration of the representation as a simpler, in comparison with investigative actions, a purely «technical» method of collecting ob-jects and documents to be attached to a criminal case as material evidence, other doc-uments, expert opinions, the results of operational investigative and administrative ac-tivities of law enforcement agencies for the purpose of subsequent use to substantiate enforcement decisions. Methodologically, starting from his previous scientific publi-cations devoted to the issues of criminal procedural proof in general and the collection of evidence in particular, the author investigates the phenomenon of the presentation of objects and documents, defines the circle of subjects initiating this procedure, con-siders the procedure for its implementation, notes the shortcomings of its legislative regulation. Particular attention is paid to the practical issues of the presentation of objects and documents in pre-trial proceedings in a criminal case. The most acceptable meth-ods and applied technologies of acceptance and transfer of potential evidence presented to the bodies of inquiry and preliminary investigation by suspects, accused, victims are analyzed and other interested participants, materials of operational-search activities, as well as items and documents submitted by «third» parties, that is, various government bodies, local local governments, their officials, enterprises, institutions and individuals.

Keywords: preliminary investigation; production; retrieval of evidence; presentation of evidence; collecting evidence; criminal procedural proof

\section{INFORMATION ABOUT AUTHORS}

\author{
Rossinskiy, Sergey B. | E-mail: s.rossinskiy@yandex.ru \\ Dr. Sci. (Jurisprudence), Professor of the Criminal \\ Procedure Dept.
}




\title{
Представление предметов и документов как способ собирания доказательств в досудебном производстве по уголовному делу
}

\author{
С. Б. Россинский ${ }^{1}$
}

${ }^{1}$ Московский государственный юридический университет имени О. Е. Кутафина, ул. Садовая-Кудринская, 9, Москва, 125993, Российская Федерация

DOI: $10.18255 / 1996-5648-2021-2-210-219$

УдК $343.14,343.01$
Научная статья Полный текст на русском языке

Настоящая статья посвящена рассмотрению представления как более простого по сравнению со следственными действиями, сугубо «технического» способа собирания предметов и документов, подлежащих приобщению к уголовному делу в качестве вещественных доказательств, иных документов, заключений специалиста, результатов оперативно-розыскной и административной деятельности правоохранительных органов с целью последующего использования для обоснования правоприменительных решений. Методологически отталкиваясь от своих прежних научных публикаций, посвященных вопросам уголовно-процессуального доказывания в целом и собирания доказательств в частности, автор исследует феномен представления предметов и документов, определяет круг субъектов-инициаторов данной процедуры, рассматривает порядок ее осуществления, отмечает недостатки ее законодательного регулирования.

Особое внимание уделяется практическим вопросам представления предметов и документов в досудебном производстве по уголовному делу. Анализируются наиболее приемлемые способы и прикладные технологии приема-передачи потенциальных доказательств, представляемых органам дознания и предварительного следствия подозреваемым, обвиняемым, потерпевшим и другими заинтересованными участниками, материалов оперативно-розыскной деятельности, а также предметов и документов, представляемых «третьими» лицами, то есть различными органами государственной власти, местного самоуправления, их должностными лицами, предприятиями, учреждениями и отдельными гражданами.

Ключевые слова: досудебное производство; истребование доказательств; представление доказательств; собирание доказательств; уголовнопроцессуальное доказывание

\section{ИНФОРМАЦИЯ ОБ АВТОРАХ}

Россинский, Сергей Борисович

(C) Россинский С. Б., 2021
E-mail: s.rossinskiy@yandex.ru Доктор юридических наук, доцент, профессор кафедры уголовно-процессуального права

Статья открытого доступа под лицензией СС ВY (https://creativecommons.org/licenses/by/4.0/) 
Россинский С. Б.

Потребность в успешном и продуктивном осуществлении органами дознания и предварительного следствия возложенных на них уголовно-процессуальных фрункций невольно побуждает законодателя к формированию целой системы правовых, в том числе юрисдикционных, механизмов, обеспечивающих накопление полезной информации, подлежащей дальнейшему использованию при обосновании правоприменительных решений. Важнейшее место среди таких механизмов, вне всяких сомнений, занимают следственные действия, то есть познавательные приемы, направленные на установление обстоятельств, имеющих значение для уголовного дела и связанные с собиранием полноценных доказательств и их депонированием для предстоящего судебного разбирательства.

Вместе с тем, как уже неоднократно отмечалось в публикациях автора настоящей статьи, далеко не все существующие виды доказательств появляются именно в ходе производства следственных действий [1, с. 71-72]; наряду с показаниями (ст. 76-79 УПК РФ) и протоколами (ст. 83 УПК РФ) законодатель предусматривает и другие средства доказывания, в частности вещественные доказательства, иные документы, заключения специалиста. Более того, в современной следственной и судебной практике достаточно активно используются результаты оперативно-розыскной и административной деятельности органов исполнительной власти, которые, не будучи отнесенными к автономным видам доказательств, тем не менее оказывают неоценимую пользу для установления различных обстоятельств, имеющих значение для уголовного дела. Все подобные доказательства «рождаются» вне процессуальных правоотношений и поступают в распоряжение органов предварительного расследования как уже сложившиеся познавательные ресурсы - в состоянии некоей «готовности к употреблению», поэтому просто приобщаются в качестве доказательств («вводятся» в уголовный процесс), или не приобщаются - в случае невозможности или целесообразности их признания средствами процессуального доказывания.

В этой связи механизмы досудебного производства по уголовному делу объективно требуют более простых, сугубо «технических» способов собирания доказательств. И одним из таких способов, как известно, является представление доказательств, состоящее в добровольной передаче следователю различных предметов и документов для приобщения к уголовному делу.

Советский уголовно-процессуальный закон наделял правом представления доказательств достаточно широкий круг субъектов. Наряду сучастниками уголовного судопроизводства такой возможностью обладали любые граждане, учреждения, предприятия и организации. Однако действующий УПК РФ пошел по несколько иному, как бы усеченному, пути. На сегодняшний день правом представления предметов и документов (доказательств) прямо наделены только подозреваемые, обвиняемые, потерпевшие, гражданские истцы, гражданские ответчики, а также защитники, представители и законные представители (в судебном заседании этим правом также наделены государственные и частные обвинители). Иными словами, возможность представ- 
ления доказательств как бы увязана с фрормально-определённым статусом соответствующего субъекта-инициатора, а также с его обязательной принадлежностью к стороне обвинения или стороне защиты.

Подобная ограниченность перечня субъектов - инициаторов представления предметов и документов - представляется несколько странной, в особенности на общем фоне прямо противоположной тенденции развития уголовно-процессуального законодательства, выраженной, в распространении предусмотренных УПК РФ диспозитивных возможностей на максимально широкий круг лиц. Так, согласно ч. 1 ст. 123 УПК РФ правом на обжалование действий (бездействия) решений субъектов уголовной юрисдикции наряду с участниками уголовного судопроизводства обладают и любые другие лица (например, поручитель, залогодатель, собственник изъятого или поверженного в ходе обыска или выемки имущества и т. д.). Эта же тенденция находит отражение и в положениях, определяющих право на апелляционное обжалование (ч. 1 ст. 398.1 УПК РФ), право на кассационное обжалование (ч. 1 ст. 401.2 УПК РФ) и т. д.

В настоящее время уже достаточно сложно сказать, что явилось причиной сужения круга лиц, управомоченных представлять доказательства. Вполне вероятно, что к этому шагу законодателя в очередной раз подтолкнуло имевшее место в 1990-е годы «заигрывание» с принципом состязательности в англосаксонском варианте, предполагающем возложение основной нагрузки по доказыванию обстоятельств уголовного дела не на суд, а именно на стороны. Возможно выдвинуть и иную гипотезу. Она состоит в том, что указанный шаг вообще был обусловлен оставлением разработчиками УПК РФ этих вопросов без должного внимания или банальным недопониманием тонкостей работы органов предварительного расследования. Не исключены и другие объяснения возникновения существующих подходов к составу субъектов, наделенных правом представления доказательств.

Вместе с тем, какая из указанных причин оказалась решающей, в сущности не так уж и принципиально. Гораздо важнее другое, а именно то, что действующий УПК РФ не позволяет удовлетворить реальные потребности правоприменительной практики, искусственно сужая круг субъектов-инициаторов, желающих представить какие-либо предметы или документы для приобщения к материалам уголовного дела.

На сегодняшний день к таким не попавшим в поле зрения законодателя субъектам можно отнести несколько категорий лиц. Во-первых, это предусмотренные гл. 8 УПК РФ «иные» ${ }^{1}$ участники уголовного судопроизводства, которые, не имея собственной фрунциональной направленности, оказывают процессуальное содействие суду, органам предварительного расследования и сторонам в реализации возложенных на них полномочий (предоставленных

${ }^{1}$ Термин «иные» применительно к обозначению обособленной группы участников уголовного судопроизводства, предусмотренных гл. 8 УПК РФ, преднамеренно берется в кавычки. Тем самым подчеркивается, что он предполагает определенную уголовно-процессуальную категорию, а не используется в значениях «другие», «остальные» и т. д. 
Россинский С. Б.

им правомочий). Наиболее ярким участником указанной группы в контексте представления предметов и документов является свидетель, который в силу своей прямой или косвенной взаимосвязи с обстоятельствами, подлежащими установлению (доказыванию) по уголовному делу, нередко становится обладателем каких-либо материальных объектов, имеющих важное доказательственное значение. Данный тезис можно подтвердить множеством примеров из практики. Так, при совершении уличного грабежа преступники похитили у потерпевшего кошелек, который после извлечения из него денег незамедлительно выбросили в ближайший мусорный бак. Случайным свидетелем произошедшего оказался местный пенсионер, наблюдавший за преступлением из окна своей квартиры. Позднее он вышел на улицу, достал из мусорного бака кошелек и лично отнес его в районный отдел внутренних дел. В другой ситуации вызванная на допрос в качестве свидетеля мать обвиняемого принесла с собой и попросила приобщить к материалам уголовного дела удостоверение о нескольких государственных наградах сына, полученных им во время прохождения воинской службы в одной из «горячих точек».

Во-вторых, это правоохранительные органы, наделенные полномочиями по осуществлению оперативно-розыскной деятельности, результаты которой подлежат представлению в орган дознания или следователю для дальнейшего использования в процессе доказывания. Кстати, правовой изъян, выраженный в отсутствии системного единства между нормами УПК РФ и положениями законодательства об оперативно-розыскной деятельности, вообще не выдерживает никакой критики и уже неоднократно поднимался в специальной литературе [2, с. 148; 3, с. 125; 4, с. 18], в том числе в публикациях автора настоящей статьи [1, с. 72]. Закон «Об ОР Д» ${ }^{2}$ и предопределённая им Инструкция «О порядке представления результатов ОРД» ${ }^{3}$ вроде бы предусматривают право соответствующих правоохранительных органов на представление для приобщения к уголовному делу материалов, фриксирующих ход и результаты проведенных ими оперативно-розыскных мероприятий, а также добытых оперативным путем предметов либо документов. Однако сам УПК РФ почему-то не содержит ни единого намека на подобную возможность, равно как и на встречную обязанность субъекта уголовной юрисдикции (следователя, а в судебном производстве - суда) принять представленные результаты оперативно-розыскной деятельности и «ввести» их в уголовное дело.

И, наконец, в-третьих, это любые другие государственные либо муниципальные органы, их должностные лица, а также фризические лица либо организации, располагающие определёнными предметами или документами

\footnotetext{
${ }^{2}$ Федеральный закон от 12 августа 1995 г. № 144-Ф3 «Об оперативно-розыскной деятельности».

${ }^{3}$ Инструкция о порядке представления результатов оперативно-розыскной деятельности органу дознания, следователю или в суд, утв. совместным приказом МВД России № 776, Минобороны России № 703, ФСБ России № 509, ФСО России № 507, ФТС России № 1820, СВР России № 42, ФСИН России № 535, ФСКН России № 398, СК России № 68 от 27 сентября 2013г. «Об утверждении Инструкции о порядке представления результатов оперативно-розыскной деятельности органу дознания, следователю или в суд».
} 
и желающие добровольно представить их в орган предварительного расследования. Современная правоприменительная практика просто изобилует подобными ситуациями. Особое место среди них занимают случаи, связанные с передачей для приобщения к материалам уголовного дела (к материалам доследственной проверки) различных результатов административной деятельности, полученных в процессе реализации своих полномочий неоперативными подразделениями органов внутренних дел, налоговыми, таможенными, антимонопольными и многими другими органами, осуществляющими контрольные и надзорные функции.

В этой связи представляется, что в сложившейся ситуации законодателю надлежит кардинально пересмотреть свое несколько поверхностное отношение к кругу субъектов, наделенных правом представления предметов и документов для приобения к уголовному делу в качестве доказательств. Такое право предлагается распространить на все вышерассмотренные категории лиц независимо от формально-определённого уголовно-процессуального статуса и тем более от принадлежности к участникам со стороны обвинения или стороны защиты.

Далее следует рассмотреть сам процессуальный порядок представления предметов и документов. В юридической литературе уже неоднократно предлагались процессуальные технологии осуществления данного способа собирания доказательств, сводящиеся, как правило, к заявлению, рассмотрению и разрешению соответствующих ходатайств [5, с. 12 ; 6 , с. 224; 7, с. 66-67]. А наиболее подробно указный порядок рассмотрен в работах В. А. Семенцова. Автор полагает, что представление предметов и документов состоит в поэтапном осуществлении следующих действий: а) доставления представляемого объекта в орган предварительного расследования (в суд); б) заявления субъектом-инициатором (лицом, доставившим предмет либо документ) соответствующего ходатайства; в) принятия (непринятия) данного предмета или документа [8, с. 109].

В целом такой алгоритм является вполне приемлемым. Однако он все же вызывает ряд возражений. Во-первых, вряд ли стоит включать в сферу уголовно-процессуального регулирования, то есть считать элементом процессуальной формы действия, связанные с доставлением субъектом - инициатором представляемых предметов или документов. Ведь указанная позиция полностью противоречит общей концепции публичных уголовно-процессуальных отношений, предполагающих обязательное участие органов дознания, предварительного следствия, прокуратуры или суда как лиц, наделенных государственно-властными полномочиями. Следуя подобной логике, в предмет уголовно-процессуального регулирования придется также вводить и все иные действия-доставления (например, доставление задержанного подозреваемого, доставление результатов контроля и записи переговоров, инфрормации о соединениях между абонентами и (или) абонентскими устройствами и т. д.). 
Россинский С. Б.

Во-вторых, сложно согласиться с точкой зрения, предполагающей возможность представления потенциальных доказательств не иначе как посредством заявления соответствующего ходатайства. Данное требование приведет к усложнению порядка передачи предметов или документов в распоряжение субъектов уголовной юрисдикции, предопределит необходимость составления еще целого ряда процессуальных документов (самого ходатайства, постановления об его удовлетворении / отказе в удовлетворении). Кроме того, правом заявления ходатайств вообще наделены строго определённые участники, как правило отстаивающие в деле собственные либо представляемые (защищаемые) интересы (ч. 1 ст. 119 УПК РФ). Причем, указанный законодательный подход является весьма разумным, поскольку появление такой возможности у более широкого или даже неограниченного круга лиц, безусловно, вызовет процессуальный хаос и негативно повлияет на количество злоупотреблений - на органы предварительного расследования и суд буквально обрушится шквал требующих обязательного рассмотрения и разрешения ходатайств.

В этой связи порядок представления предметов и документов требует дифференциации - в зависимости роли субъекта-инициатора в уголовном деле и наличия у него определённого процессуального статуса. $К$ слову, идею такой дифференциации высказывали еще Н. В. Жогин и Ф. Н. Фаткуллин, которые писали даже не о двух, а трех различных способах представления доказательств: а) подозреваемым, обвиняемым, защитником, потерпевшим, гражданским истцом, гражданским ответчиком и их представителями; б) общественными и самодеятельными организациями трудящихся; в) отдельными гражданами, не участвующими в уголовном судопроизводстве [9, с. 155-157].

Для подозреваемого, обвиняемого, защитника потерпевшего и иных заинтересованных участников уголовного судопроизводства, наделенных правом доступа к правосудию, наиболее рациональным действительно является предлагаемый В. А. Семенцовым алгоритм передачи потенциальных доказательств посредством заявления соответствующего ходатайства. Однако в части других субъектов-инициаторов подобную процедуру разумнее свести к более простым формам, обусловленным общими правилами обращения в органы государственной власти и технологиями делопроизводства. Например, для передачи органам предварительного расследования материалов, содержащих результаты оперативно-розыскной деятельности, целесообразнее всего придерживаться «традиционной» технологии, вытекающей из содержания Инструкция «О порядке представления результатов ОРД» - на основании специального сопроводительного письма, включающего сведения о назначении направляемых материалов, их опись и обстоятельства их получения (приложение № 1 к Инструкции). Подобный порядок может быть использован и для представления предметов и документов иными государственными либо муниципальными органами, их должностными лицами, а также различными предприятиями, учреждениями, организациями. 
Для граждан либо иных фризических лиц, не являющихся заинтересованными в исходе дела участниками уголовного судопроизводства, лучше использовать несколько иную технологию передачи следователю представляемых предметов или документов - посредством подачи заявления как юридического приема, отвечающего общим правилам «первичного» обращения в государственные органы. Кстати, подобные позиции, но с определёнными оттенками можно встретить и в работах некоторых других авторов [7, с. 67; 10 , с. $10 ; 11$, с. 69 ]. Ввиду необходимости создания режима наибольшей комфортности для лиц, желающих представить какие-либо объекты в распоряжение органа предварительного расследования, разумно предусмотреть как письменную, так и устную фрорму заявления; последнюю, в частности, возможно использовать в ходе производства следственного действия и фиксировать в соответствующем протоколе (например, для передачи предмета либо документа свидетелем во время допроса или лицом, присутствующим при производстве следственного осмотра, обыска и т. д.).

Ну, и наконец, в-третьих, излишним видится предлагаемое В. А. Семенцовым обязательное протоколирование передачи предметов или документов, посредством которого автор предлагает фиксировать завершающий этап процедуры представления - принятие (непринятие) потенциальных доказательств субъектом уголовной юрисдикции. Эта идея обосновывается необходимостью отражения в материалах уголовного дела всех участвующих лиц, самой процедуры представления, описания индивидуальных признаков передаваемых объектов и других существенных обстоятельств [8, с. 115]. Близкие позиции можно встретить в публикациях С. А. Шейфрера, В. В. Кальницкого и Е. Г. Ларина, а также некоторых иных ученых [12, с. 139; 13, с. 103].

Однако, на наш взгляд, такой механизм будет являться неоправданно «тяжелым» и лишь приведет к излишним бюрократическим фрормальностям. Да и вообще необходимость полноценного протоколирования представления предметов и документов во многом уподобляет его следственным действиям, то есть как бы сводит на нет поддерживаемые теми же С. А. Шейфрером, В. А. Семенцовым и другими авторами совершенно разумные идеи о более простом характере данного способа собирания доказательств. Все-таки протокол - это не заурядное «техническое» свидетельство, удостоверяющее фракт получения чего-либо адресатом; это не расписка, не акт приема-передачи, не отметка о вручении на сопроводительном письме и т. д. По смыслу закона уголовно-процессуальные протоколы (в частности протоколы следственных действий) - это документы, фрксирующие какие-либо новые сведения, имеющие значение для уголовного дела, в первую очередь полученные в результате поисково-познавательной деятельности органов предварительного расследования. Вместе с тем процедура представления не подразумевает процессуального познания, не связана с формированием новых доказательств, а сводится к сугубо «технической» передаче «готовых к употреблению» информационных ресурсов в распоряжение субъектов уголовной юрисдикции. Конечно, представляемые предметы и документы в дальнейшем становятся 
Россинский С. Б.

объектами тщательного следственного и судебного познания (исследования, проверки), предполагающего то самое полноценное восприятие их фрормы, содержания и других индивидуальных признаков, о котором пишет В. А. Семенцов, - в противном случае они просто не могут быть признаны доказательствами и использоваться для основания правоприменительных решений. Но это уже следующий этап работы с указанными предметам и документами, обусловленный их нахождением в законном ве́дении следователя.

Конечно, для справедливости стоит отметить, что авторы, ратующие за обязательное протоколирование процедуры представления, зачастую руководствуются совершенно иными соображениями. Они пытаются сконструировать дополнительные процессуальные гарантии индивидуализации приобщаемых к уголовному делу предметов или документов и, таким образом, минимизировать риски возможных следственных ошибок либо фральсиорикаций. Эта процедура, писал С. А. Шейфер, необходима для предотвращения вероятных нареканий о подмене объекта или жалоб на необоснованный отказ в его приобщении к делу [13, с. 103].

Однако, на наш взгляд, столь серьезная юридическая «страховка» требуется далеко не всегда. В большинстве случаев процессуальная доброкачественность представляемых предметов или документов вполне может быть обеспечена и более простыми способами, сводящимися к общим правилам делопроизводства и документооборота. В частности, необходимые для индивидуализации признаки (реквизиты документа, общее описание предмета и т. д.) обязательно указываются в сопроводительном письме государственного (муниципального) органа, должностного лица либо организации; эти же признаки могут содержаться и в ходатайстве подозреваемого, обвиняемого, защитника, потерпевшего или иного заинтересованного участника уголовного судопроизводства и в заявлении любого другого фризического лица. А в случае представления предмета либо документа в ходе производства следственного действия эти признаки надлежит фриксировать прямо в соответствующем протоколе. Кроме того, в следственной практике может быть использован и дополнительный «страховочный» документ - специальный акт приема-передачи, составляемый по желанию как передающей, так и принимаюей стороны.

Между тем все же не следует полностью исключать ситуации, объективно требующие более существенные правовые гарантии обеспечения сохранности добровольно передаваемых следователю объектов и, таким образом, предопределяющие необходимость составления некоего протокола в порядке, предусмотренном ст. 166 УПК РФ. В частности, А. М. Ларин в свое время относил к подобным объектам предметы и документы, являющиеся незаменимыми ввиду индивидуальных свойств и признаков, а также составляющие материальную или духовную ценность (творческие рукописи, дневники, личные письма, сувениры и пр.) [14, с. 67]. С предлагаемым перечнем согласиться достаточно сложно хотя бы потому, что на сегодняшний день он уже во многом утратил свою актуальность и требует существенного пересмотра 
с учетом реалий жизнедеятельности современного общества и государства. Но в главном автор был абсолютно прав: представление органу предварительного расследования особо «ценных» объектов должно предполагать обязательное протоколирование. При этом ученый предлагал ввести в предмет уголовно-процессуального регулирования новое следственное действие «принятие представленного предмета (документа)». Однако, на наш взгляд, для решения указанных задач как нельзя лучше подходит выемка, которая уже неоднократно рассматривалась нами как еще один сугубо технический прием, направленный на «введение» различных предметов и документов в уголовное дело; к проблемам ее сущности и производства мы планируем возвращаться и в дальнейшем.

\section{Ссылки}

1. Россинский С. Б. Проблема использования в уголовном процессе результатов оперативно-розыскной деятельности требует окончательного разрешения // Lex russica (Русский закон). 2018. № 10 (143). С. 70-84.

2. Ежова Е. В. Проблемы раскрытия преступлений в современной России. Уфа: БашГУ, 2008. 226 с.

3. Николюк В. В. Проблемы взаимосвязей уголовно-процессуального законодательства с иными законами о противодействии преступности // Правовые проблемы укрепления Российской государственности: материалы Всероссийской научно-практической конференции. Томск: ТГУ, 2018. Ч. 79. С. 123-126.

4. Смирнов А. В. «Серебряное блюдо» оперативно-розыскной деятельности // Уголовный процесс. 2012. № 10. С. 12-18.

5. Воронина Л. В. Протоколы и иные документы как источники доказательств в советском уголовном процессе (по материалам Казахской ССР): автореф. дис. ... канд. юрид. наук. Л.: ЛГУ им. А. А. ЖЖданова, 1987. 23 с.

6. Демурчев Л. Г. Представление документов и предметов участниками уголовного процесса на предварительном расследовании // Общество и право. 2011. № 2 (34). C. $223-226$.

7. Костенко Р. В. Сущность представления доказательств в российском уголовном процессе // Библиотека криминалиста: научный журнал. 2012. № 2 (3). C. $65-73$.

8. Семенцов В. А. Следственные действия в досудебном производстве. М.: Юрлитинформ, 2017. 256 с.

9. Жогин Н. В., Фаткуллин Ф. Н. Предварительное следствие в советском уголовном процессе. М.: Юрид. лит., 1965. 367 с.

10. Кондратьева T. X. Представление доказательств участниками уголовного судопроизводства: автореф. дис. ... канд. юрид. наук. Краснодар: КубГАУ, 2009. 29 c.

11. Мамедов Р. Я. Представление вещественных доказательств всистемеспособовсобираниядоказательстввдосудебномуголовномсудопроизводстве // Апробация. 2015. № 4 (31). С. 68-71.

12. Кальницкий В. В., Ларин Е. Г. Следственные действия: учеб. пособие. Омск: ОмА МВД России, 2015. 172 с.

13. Шейфер С. А. Доказательства и доказывание по уголовным делам: проблемы теории и правового регулирования. М.: Норма, 2008. 240 с.

14. Ларин А. M. Истребование и представление предметов и документов в стадии расследования // Актуальные проблемы совершенствования производства следственных действий: сб. науч. тр. Ташкент: Ташкентская ВШ МВД СССР, 1982. С. 62-68. 